\title{
The Influence of the Culture of the Scientific Community on the Methodology of Economic Science
}

\author{
Evgeny Popov \\ Ural Federal University named after the first President of Russia B.N.Yeltsin, Ekaterinburg, Russia, Head of the Centre of Economic \\ Theory, Institute of Economics, Ural Branch of the Russian Academy of Sciences, Ekaterinburg; epopov@mail.ru \\ Maxim Vlasov \\ Ural Federal University named after the first President of Russia B.N.Yeltsin, Ekaterinburg, Russia, Senior Fellow at the Centre of \\ Economic Theory, Institute of Economics, Ural Branch of the Russian Academy of Sciences, Ekaterinburg; Mvlassov@mail.ru
}

Doi:10.5901/mjss.2015.v6n6s4p236

\section{Abstract}

Tendencies in the development of the culture of the scientific community over the last decade are identified according to an analysis of keywords of articles indexed in the Scopus database. In order to determine development trends in the methodology of economic science, an evaluation of the research topics of Nobel Economics Prize laureates of the 21st century was carried out. Comparison of the development trends of the culture of scientific community and the research topics of Nobel Prize laureates allows for inferences to be drawn concerning the future direction of economic science.

Keywords: economic science, economic methodology, scientific culture, development, knowledge.

\section{Introduction}

The rapid development of economic instruments generates the necessity for assessing changes in the methodology of economic science due to the development of the culture of the scientific community. The relevance of this study is due, in the first instance, to the formation of the broadest scientific instruments and the emergence of previously unknown methods of economic analysis, and, secondly, to a change in the primary methods of economic research from orthodox, neoclassical analysis to a more heterodox approach towards the study of economic systems. However, there is very little research published in the economic scientific literature on the formation of methodological aspects of economic science caused by changes in the culture of the scientific community.

The purpose of this study is to determine the impact of major trends in the development of scientific culture on changes in the methodology of economic science during the 21st century.

\section{Development of the Methodology of Economic Science}

The methodology of economic science consists of the knowledge of the methods of economic research, i.e. the knowledge of methods of describing objects and research subjects as well as tools for studying economic activity.

The development of modern economic theory has led to a serious conflict between the tools developed and those actually applied. On the one hand, the global and domestic economic literature has accumulated a considerable arsenal of methods and tools for modelling business activities. On the other hand, the advanced contemporary economic toolset is extremely fragmented and lacks a system. Over the coming years there will be strong possibilities for the theoretical systematisation of economic instruments, both in terms of methods of analysis and objects of research (Popov, 2005).

As for the current methods of theoretical economic analysis, the most promising comprise neoclassical, institutional, neo-institutional and evolutionary approaches. Moreover, theoretical studies indicate that these areas of economic analysis are essentially compatible with actual economic activity. However, the last three tendencies can easily be interpreted in terms of institutional-evolutionary economics, since the development of institutional systems can be adequately described according to an evolutionary approach.

In this sense, the insight of $\mathrm{T}$. Veblen that economics is based on the activities of institutions as "stable habits of thought inherent in a large community of people"(Veblen, 1919) has played its choreographed role in shaping modern 
views on economic theory. Neoclassical theory, considered as the "mainstream" economic theory of the late twentieth century, has gone by the wayside due to the significant number of limitations it places on the assessment of the analysed events. The requirement for the rational behaviour of economic agents, the analysis of factors exogenous to the economic subjects and the evaluation of limiting parameters at a steady state resulted in a situation where the neoclassical trend is now seen at best as a necessary exercise for university students. The real economic situation can be most adequately described within the framework of the institutional-evolutionary approach. This approach permits the analysis of complex, non-equilibrium situations, for example, the dynamics of the formation and development of institutional traps; consequently, it has greater predictive power than the neoclassical approach.

Model approaches towards institutional economic theory have determined the development of transactional theories of economic institutions (Popov, 2014). The principal content of the theory consists in the quantification of the quality of institutions through the evaluation of economic transactions. The transactional theory of economic institutions is based on the following scientific principles:

- the boundedness of transactions according to John Commons(Commons, 1931),

- the formation of the transactional sector according to John Wallis and Douglas North (Wallis\&North, 1986),

- the non-production nature of transaction costs according to Robert Matthews (Matthews, 1986),

- the proportionalities of transaction costs of asset specificity according to Oliver Williamson (Williamson, 1991),

- the minimisation of transactions in the formation of economic institutions according to Ronald Coase (Coase, 1937).

Scientific ideas are advanced in terms of original development of the theory on the typology of transactions, evaluation of crises, definition of transaction costs on financial statements, assessing the closeness of ties hybrid organisations and the evaluation of economic institutions according to transaction costs (Popov, 2014).

The transition from the instrumental apparatus of (orthodox) neoclassical economics theory to institutionalevolutionary ideas concerning economic activity led to the creation of the international Association for Heterodox Economics at the beginning of this century ${ }^{1}$.

How is it possible to evaluate changes in the methodology of economics? It is probable that the most adequate assessment of these changes can be achieved by analysing the topics of study of Nobel economics prize laureates. In this connection, it is assumed that the Royal Swedish Academy of Sciences announces the names of laureates whose studies are of greatest interest to the scientific community in the year of the award of the corresponding Nobel Prize.

\section{Research Procedures}

In terms of the research topic, authors chose a selection of articles from those registered in the Scopus database. Keyword research can define the relative growth index of economic articles PI on the topic K (keyword) based on a simple ratio:

$P I_{K}=P(2014)_{K} / P(2006) K$

Where $P(2014) K$ and $P(2016) k$ represent the number of items registered in the Scopus database for topic $K$ (keyword) in 2014 and 2006, respectively. Authors chose 2006 as the basis for the calculation from the availability of the data in the Scopus database.

Selected keywords are correlated to the subject matter of the research of Nobel Economics Prize laureates in the years from 2000-2014. From this we can determine the time dependence of the change of research topics priority for Nobel laureates. A comparison of the relative growth of indexes of articles and the time dependence of the changes of research topics priority for Nobel economics prize laureates allows for drawing conclusions concerning the possible formation of the future direction of economic science.

\section{Results of the Study}

Using the keywords of articles registered in the Scopus database, the relative growth of indexes of articles on selected topics of research were determined (Table. 1).

\footnotetext{
${ }^{1}$ www.hetecon.net
} 
Table 1. Number of articles and growth in indexes of articles $\mathrm{PI}_{\mathrm{K}}$ by keyword $\mathrm{K}$ in $2006-2014$. $^{2}$

\begin{tabular}{|l|c|c|c|c|c|c|c|c|c|c|}
\hline \multirow{2}{*}{$\mathrm{K}$} & \multicolumn{9}{|c|}{ Years } & \multirow{2}{*}{$\mathrm{P}_{\mathrm{K}}$} \\
\cline { 2 - 15 } & 2006 & 2007 & 2008 & 2009 & 2010 & 2011 & 2012 & 2013 & 2014 & \\
\hline Innovations & 51 & 72 & 90 & 109 & 107 & 114 & 153 & 139 & 163 & 3.20 \\
\hline People & 51 & 54 & 93 & 70 & 110 & 132 & 165 & 174 & 132 & 2.59 \\
\hline Corporate governance & 62 & 72 & 106 & 120 & 115 & - & 144 & - & 152 & 2.45 \\
\hline Economic growth & 86 & 89 & 133 & 136 & 160 & 186 & 197 & 221 & 209 & 2.43 \\
\hline Financial crisis & - & - & - & 75 & 75 & 102 & 165 & 174 & 182 & 2.42 \\
\hline Education & 49 & - & - & - & 69 & 85 & 77 & 89 & 133 & 1.93 \\
\hline Supply chains & - & - & 73 & 116 & 112 & 87 & 94 & 96 & 136 & 1.89 \\
\hline Economic theory & 54 & 61 & 99 & 85 & 87 & - & - & - & - & 1.61 \\
\hline Monetary policy & 99 & 103 & - & - & - & 123 & 114 & 143 & 140 & 1.41 \\
\hline Costs & 79 & - & - & - & - & 72 & 89 & 97 & 105 & 1.33 \\
\hline
\end{tabular}

A simple analysis of Table 1 shows a significant correlation between the research topics and the financial crisis of 20082009. It is evident that prior to the financial crisis there had been no publications with the key words "financial crisis." The themes of "monetary policy" and "costs" were similarly not referred to in the keywords of articles published between 2008-2010. On the other hand, research on economic theory fell sharply after 2010. Authors assumed that economictheoretical studies were unable to provide an adequate model of economic activity at a time of financial crisis.

Verification of research concerning the winners of the Nobel Economics Prize laureates between 2000 and 2014 was based on keywords of articles registered in the Scopus database (Table. 2). From the data, it is clear that the research topics of Nobel Economics Prize laureates have increasingly been linked to seven key words. In this connection, the research priorities of "Nobel laureates" in the XXI century continue to feature the keywords "innovation", "financial crisis" and "education".

Table 2: Selected keywords correlated to the subject matter of the research of Nobel Economics Prize laureates in the years from 2000-2014 taken from articles in the Scopus database ${ }^{3}$

\begin{tabular}{|l|l|l|l|}
\hline Year & Nobel Prize winners & Prize-giving rationale & K \\
\hline 2000 & J. Heckman, D. McFadden & $\begin{array}{l}\text { For the development of theory and methods for analysing discrete } \\
\text { choice }\end{array}$ & $\begin{array}{l}\text { Supply chains } \\
\text { Supply chains }\end{array}$ \\
\hline 2001 & G. Akerlof, M. Spence, J. Stiglitz & For the analysis of markets with asymmetric information & Supply chains \\
\hline 2002 & D. Kahneman, V. Smith & $\begin{array}{l}\text { For research in the area of decision-making and alternative market } \\
\text { mechanisms }\end{array}$ & Supply chains \\
\hline 2003 & R. Engle, C. Granger & For the development of a time series analysis method in economics & Monetary policy \\
\hline 2004 & F. Kydland, E. Prescott & $\begin{array}{l}\text { For their contribution to the influence of the time factor on economic } \\
\text { policy }\end{array}$ & Economic growth \\
\hline 2005 & R. Aumann, T. Schelling & $\begin{array}{l}\text { For deepening the understanding of conflict and cooperation } \\
\text { through game-theory analysis }\end{array}$ & $\begin{array}{l}\text { Overall management } \\
\text { Corporate governance }\end{array}$ \\
\hline 2006 & E. Phelps & For his analysis of intertemporal tradeoffs in macroeconomic policy & Economic theory \\
\hline 2007 & L. Hurwicz, E. Maskin, R. Myerson & For having laid the foundations of mechanism design theory & Monetary policy \\
\hline 2008 & P. Krugman & For the analysis of trade structures and location of economic activity & $\begin{array}{l}\text { Costs } \\
\text { Costs }\end{array}$ \\
\hline 2009 & E. Ostrom, O. Williamson & For research in the field of economic organisation & Costs \\
\hline 2010 & P. Diamond, D. Mortensen, C. & For market research with search models & Supply chains \\
\hline 2011 & T. Sargent, C. Sims & For empirical studies of cause and effect in the macroeconomy & Economic growth \\
\hline 2012 & L. Shapley, A. Roth & For the theory of stable allocations and practice of market design & Supply chains \\
\hline 2013 & E. Fama, L.P. Hansen, R. Schiller & For the empirical analysis of the changes in asset prices & Costs \\
\hline 2014 & J. Tyrol & For the analysis of market power and its regulation & Supply chains \\
\hline
\end{tabular}

A graphical comparison of the indices of growth of Scopus articles by keyword and research topics Nobel laureate in economics is provided in the diagram showing the timing of prizes (Fig. 2).

${ }^{2}$ Carried out by the author according to figures from the site www.scopus.com

${ }^{3}$ Carried out by the author according to figures from the site $h$ ttps://ru.wikipedia.org/wiki 


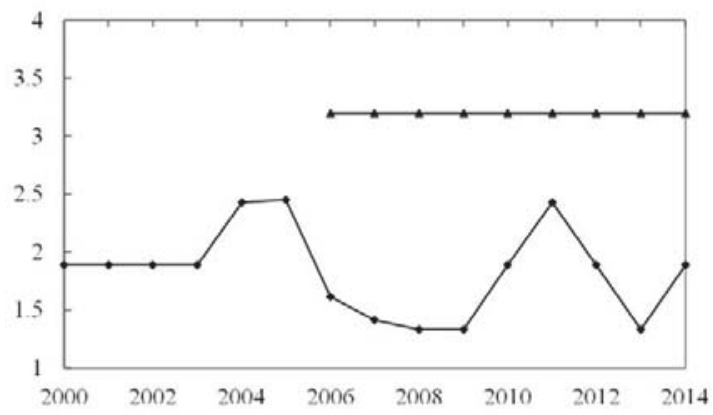

Figure 2. Dependence of the index of growth of articles $\mathrm{PI}_{\mathrm{K}}$, relevant research topics of Nobel laureates in economics, from the year of the award. Upper straight line - change in $\mathrm{Pl}$ for articles on the subject of innovation.

Figure 2 clearly shows the lag of growth in the index of articles on keyword research topics by "Nobel laureates" from the growth index of articles on the subject of innovation. The same lag is observed on the subject of "person" as well as individual research approaches taken by "Nobel laureates" to the themes of "growth" and "financial crisis." There is a paradox in terms of the lag of the economic science methodology in response to changes in the culture of the scientific community (Panikarova at all, 2015).

\section{Results and Discussion}

It should be acknowledged that the data used in this research model has a very conditional character; therefore, change in the index of growth of articles is only one of the possible indicators of the scientific community culture and can only reflect this culture weakly. However, the results obtained allow us to formulate several conclusions.

Firstly, the lag in the methodology of economic science, reflected in the writings of Nobel economics laureates from the development of the culture of the scientific community is primarily due to the time lag in recognising the work of "Nobel laureates." Indeed, the award of the Nobel Prize only occurs when the entire scientific community is already familiar with the works of the winner and there has been a "critical mass" of positive feedback on the studies of the nominee. One of the clearest examples of this time lag was the Nobel Prize awarded to Ronald Coase in 1991 for his work "Nature of the Firm", first published in 1937.

Secondly, our results demonstrate the growing interest of the Royal Swedish Academy of Sciences in awarding the Nobel Prize in Economics for work done on themes that are more contemporary. Based on the data from Table 1 and Fig. 2, we should expect the winners of the award in the coming years to include those whose research themes correspond to the keywords "innovation", "people" and "economic growth." This in turn will imply a shift in the methodology of economic science towards the direction of methods of evolutionary economics, behavioural science and the institutional paradigm (Panikarova, 2014).

Thirdly, the lag of the methodology of economics as compared to changes in the culture of the scientific community should not be seen as a paradox but rather as a reflection of knowledge development patterns. In our view, it represents a process of catching up with one another. In this connection, the culture of the scientific community, which determines the development of institutions and their activities in the field of scientific publication and mobility, is defining with respect to the methodology for studying the formation of economic systems, shown in changes in the tools and objects of study.

\section{Conclusion}

The attribution of the influence of the main trends in the development of scientific culture on changes in the methodology of economic science in the twenty-first century obtained the following theoretical and practical results.

The considerable time lag between the researches of Nobel economics laureates and the development of the scientific community culture is due to the temporal delay in recognising the work of Nobel laureates. Based on the comparison of the indices of growth of articles by keyword in the Scopus database, we can expect an offset in the methodology of economic science towards the direction of evolutionary economics methods, behavioural science and the institutional paradigm. 
It is recognised that the culture of the scientific community, which determines the development of institutions and their activities in the field of scientific publication and mobility, is defining with respect to the methodology for studying the formation of economic systems (Panikarova, 2015). Thus, the relationship between the development of the scientific community culture and the formation of the methodology of economic science is seen in terms of a process of catching up with each other in determining the main trends in the description and modelling of business activities.

\section{Acknowledgment}

The study was financially supported by the Russian Science Foundation at Udmurt State University (Izhevsk, Russia), project No. 15-18-00049.

\section{References}

Asheim B.T. and Coehen L. Contextualising Regional Innovation Systems in a Globalising Learning Economy //Journal of Technology Transfer. 2006. Vol. 31. P. 163-173.

Bell D. The Coming of Post-Industrial Society: A Venture of Social Forecasting. N.Y.: Basic Books, 1973

Clark B.R. The Higher Education System: Academic Organization in Cross-National Perspective. Berkley: University of California Press, 1983. p. 315

Coase R.H. The Nature of Firm //Economica, 1937, Vol. 4. N 10. P. 386-405.

Commons J.R. Institutional Economics //American Economic Review. 1931. Vol. 21. N 4. P. 649-672.

Drucker P. F. The Theory of the Business//Harvard Business Review. 1994. Sept. -Oct.

Kyriacou A.P., Velasques F.J.L. Inequality and Culture in a Cross-Section of Countries //Journal of Institutional Economics. 2015. Vol. 1. N 1. P. 141-166.

Laestadius S. Technology Level, Knowledge Formation and Industrial Competence in Paper Manufacturing, in G. Eliasson and C. Green (eds.), The Micro Foundations of Economic Growth, Ann Arbour: The University of Michigan Press, 1998. P. 212-226

Lundvall B.-A. and Borras S., The Globalising Learning Economy: Implications for Innovation Policy, Luxembourg: European Communities, 1997.

Matthews RCO The Economics of Institutions and Sources of Growth // Economic Journal. 1986. Vol. 96. N 12. pp. 903-910.

Nightingale P. A. Cognitive Model of Innovation //Research Policy, 1998, Vol. 27. P. 689-709.

Nonaka I., Takeuchi H. The Knowledge Creating Company, Oxford - New York: Oxford University Press, 1995.

Polterovich V. Institutional Traps: How to Get Out? I/The 5th International Symposium on Evolutionary Economics, Pushchino. Moscow: Institute of Economics, 2003. P. 130-143.

Panikarova, S. Status of the indigenous regions in Russia: The case of Khakas people // Asia-Pacific Social Science Review. 15 (1), pp. $141-148,2015$

Panikarova, S. Evolution of traditional economic institutions for Aboriginal Nations // Conference Proceedings: 8th International Days of Statistics and Economics Location: Prague, CZECH REPUBLIC Date: SEP 11-13, 2014, Pages: 1094-1105, Published: 2014

Panikarova S., Ivanova A., Williams D. Efficiency factors of educational entrepreneurial programs / S. Panikarova, A. Ivanova, D. Williams // Actual Problems of Economics. - 2015. - 6 (168) - pp. 305-315

Popov E. Transaction Estimation of Institutions //Advances in Economics and Business. 2014. Vol. 2.N 1. pp. 58-64.

Popov E., Vlasov M., Veretenikova A. Institutional Matrix of Knowledge Generation //Proceedings of the 12th European Conference of Knowledge Economy. University of Passau, Germany. UK: Academic Publishing Ltd, 2011. pp 780-789.

Popov E.V. Minieconomics as a Separate Part of Microeconomics //Atlantic Economic Journal, 2005, vol. 32, N 3, pp 133

Popov E.V., Vlasov M.V. Economic Institutions of Russian Academic Science //Mediterranean Journal of Social Sciences. 2015. Vol. 6. No 3. pp. 617-626.

Popov E.V., Vlasov M.V., Shishkina A.Y. Assessment of Intellectual Share in Profit //Actual Problems of Economics. 2015. N 2. P. 220229.

Popov E.V., Vlasov M.V., Veretenikova A.Y. Knowledge Generation within a Firm as an Object of Institutional Design //Actual Problems of Economics. 2013. N 1. pp. 463-478.

Schumpeter J.A. The Theory of Economic Development: An Inquiry into Profits, Capital, Credit, Interest and the Business Cycle. N.Y.: Oxford University Press, 1969. P. 132.

Shibayama S. Academic Commercialization and Changing Nature of Academic Cooperation // Journal of Evolutionary Economics. 2015. Vol. 25. N 3. P. 513-532.

Veblen T. The Place of Science in Modern Civilization and Other Essays. N.Y. : Huebsch, 1919. P. 239.

Wallis J., North D. Measuring the Transaction Sector in the American Economy, 1870-1970 //Long-Term Factors in American Economic Growth, Ed. by S. L. Engerman and R.E. Gallman. Chicago; University of Chicago Press, 1986. P. 95-148.

Williamson O.E. Strategizing, Economizing and Economic Organization //Strategic Management Journal. 1991. Vol. 12.N 1, P. 75-94. 